\title{
Biological variation of free plasma amino acids in healthy individuals
}

\author{
Zoraida Corte $^{1}$ and Rafael Venta ${ }^{1,2, *}$ \\ ${ }^{1}$ Servicio de Análisis Clínicos, Hospital San Agustín, \\ Avilés, Principado de Asturias, Spain \\ ${ }^{2}$ Department of Biochemistry and Molecular Biology, \\ University of Oviedo, Principado de Asturias, Spain
}

\begin{abstract}
Background: Biological variation data for free plasma amino acids are lacking from the more comprehensive databases. Therefore, we determined the intra- and inter-individual components of variation in healthy subjects. These data were used to define desirable goals for imprecision, bias and total error, indices of individuality and reference change values.

Methods: Plasma samples were collected from 11 volunteers at weekly intervals over 5 weeks. Free plasma amino acids were analyzed by reversed-phase HPLC and analytical and biological variation data were derived using ANOVA.

Results: Intra-individual coefficients of variation ranged from $9.5 \%$ to $46.4 \%$, with lower values among the essential amino acids. The mean inter-individual coefficient of variation was $46.6 \%$ and was higher than intra-individual values for all amino acids. Thus, indices of individuality were below 0.8. Reference change values ranged from $30.9 \%$ to $128.4 \%$ and total error values ranged from $15.2 \%$ to $61.0 \%$.

Conclusions: Plasma amino acids exhibit relatively low intra-individual coefficients of variation, with essential amino acids showing tighter homeostatic control. Analytical quality goals can be reasonably achieved with current methods. Reference intervals are of limited value in the detection of unusual results in an individual. Therefore, comparison of serial results by means of the reference change values is recommended.
\end{abstract}

Clin Chem Lab Med 2010;48:99-104.

Keywords: analytical quality specifications; biological variation; plasma amino acids.

\section{Introduction}

Measurement of free plasma amino acids has been used as a useful biochemical parameter for the diagnosis, prognosis

*Corresponding author: Dr. Rafael Venta, Servicio de Análisis Clínicos, Hospital San Agustín, Camino de Heros 6, 33400 Avilés, Asturias, Spain

Phone: + 34985123 014, Fax: + 34985123 025,

E-mail: rafael.venta@sespa.princast.es

Received July 15, 2009; accepted September 10, 2009;

previously published online November 25, 2009 and clinical management of inborn errors of amino acid metabolism (1-4). In addition, in adults they are used primarily in the assessment of nutritional status (4-7). In recent years, the importance of nutritional status in patients with chronic renal or liver disease has been emphasized by studies that relate malnutrition with increased morbidity and mortality. Thus, nutritional status as assessed by plasma concentrations of amino acids in predialysis patients has been considered to be a predictor for prognosis in the first period of dialysis (8-10). Also, nutritional related imbalances of free plasma amino acids before transplant surgery in patients with chronic liver disease have been associated with a higher rate of complications and a decreased overall survival rate following transplantation $(11,12)$.

Correct interpretation of changes in the plasma amino acid profile in these situations would benefit from knowledge of the inherent random variation in plasma concentrations, usually termed biological variation. Within-subject or intra-individual biological variation could be described as the average random fluctuation around a homeostatic setting point. Between-subjects or inter-individual biological variation is defined as the difference between the set-points of individuals $(13,14)$. Quantitative data of the components of biological variation have been used to assess the utility of population-based reference intervals through the index of individuality (II) $(15,16)$, and to calculate the reference change value (RCV) required for the assessment of the significance of changes in serial results from an individual (17, 18). Likewise, it has been suggested that desirable analytical quality specifications are best based on components of biological variation $(19,20)$.

The method commonly employed in clinical laboratories for the analysis of free plasma amino acids is automated ionexchange chromatography (IEC) in combination with postcolumn ninhydrin detection. This methodology provides simplicity in sample preparation and high reproducibility, being considered the reference method $(21,22)$. However, the long analytical run time is the main drawback $(22,23)$. Reversed-phase high-performance liquid chromatography (RP-HPLC) has been used as an alternative due to its higher sensitivity, versatility and speed of analysis. The most common RP-HPLC methods involve precolumn derivatization with phenylisothiocyanate (PITC) or o-phthalaldehyde (OPA). OPA methods have been proposed for measurement of primary amino acids in physiological fluids, while PITC methods have been recommended when both primary and secondary amino acids are being determined (22).

Objective quality specifications for imprecision (I), bias (B) and total error (TE) of these measurements have not been defined. In addition, data regarding the biological variation 
of free plasma amino acids have not been documented in the more comprehensive biological variation databases $(24,25)$. This lack of reliable biological variation data could be related to technical complications associated with the measurement of plasma amino acids. In particular, the long analytical run time in the IEC method may have hampered the application of experimental models recommended for the study of biological variation (13).

In the present study, we used a RP-HPLC method with PITC pre-column derivatitazion to obtain data on biological variation (intra- and inter-individual) for free plasma amino acids in apparently healthy persons. The data were used to define analytical quality specifications (I, B, TE), to assess the usefulness of population-based reference intervals, to evaluate the significance of changes in serial results from an individual, and to establish the number of specimens required to estimate the homeostatic setting point of an individual (NHSP).

\section{Materials and methods}

\section{Subjects and samples}

Eleven apparently healthy volunteers ( 8 females and 3 males; age range, 21-50 years) were recruited for this study. During the study period, all maintained their usual lifestyles. The study was performed in accordance with the Helsinki Declaration and the design and execution of the experiment were explained thoroughly to the participants, and informed consent was obtained.

Once weekly for 5 weeks and at the same time of the day (8:30-10:00), blood samples were obtained from each volunteer (only 4 weeks in one subject) under standardized conditions to minimize sources of preanalytic variation. Samples were collected, following an overnight fast, into evacuated lithium heparin gel tubes (Vacuette, Greiner Bio-one, Kremansmünster, Austria), with subjects in a sitting position and avoiding venous stasis. All specimens were immediately centrifuged at $3500 \mathrm{~g}$ for $10 \mathrm{~min}$ at room temperature. Plasma samples were aliquoted and stored at $-80^{\circ} \mathrm{C}$ for a maximum of three months before analysis.

\section{Analytical method}

Measurements of amino acid concentrations in heparinized plasma samples were performed using gradient RP-HPLC with the Pico Tag method (Waters, Milford, MA, USA) according to manufacturer's specifications (26) with a Breeze HPLC analytical system from Waters. All chemicals and solvents were purchased from SigmaAldrich (Saint Louis, MO, USA) and Merck (Darmstadt, Germany), respectively. HPLC-grade water was obtained from a MilliQ system from Millipore (Bedford, MA, USA). A solution of methionine sulfone, $400 \mu \mathrm{mol} / \mathrm{L}$ in $0.1 \mathrm{~mol} / \mathrm{L} \mathrm{HCl}$, was used as internal standard and the calibration mixture consisted of two commercial solutions of acid-neutral and basic amino acids in $\mathrm{HCl} 0.1 \mathrm{~mol} / \mathrm{L}$, plus a solution of glutamine in water. The concentration of each amino acid in the final mixture was $400 \mu \mathrm{mol} / \mathrm{L}$, except for cystine which had a concentration of $200 \mu \mathrm{mol} / \mathrm{L}$.

Prior to analysis, all samples were thawed at room temperature and mixed to ensure homogeneity. Using pre-rinsed $(0.1 \mathrm{~mol} / \mathrm{L} \mathrm{HCl})$ filter devices (Microcon Ultracel YM-10, Millipore), $400 \mu \mathrm{L}$ of each sample, diluted 1:1 with internal standard, were deproteinized by ultrafiltration through a regenerated cellulose membrane with a molecular weight $\left(M_{\mathrm{r}}\right)$ limit of 10,000 . Deproteinized samples $(50 \mu \mathrm{L})$ were derivatizated with PITC by means of three steps of evaporation to dryness in a vacuum station (Waters). The first drying step was performed on the calibration mixture and sample ultrafiltrates. A second drying step was performed following treatment with $10 \mu \mathrm{L}$ of a solution of methanol $(1 \mathrm{~mol} / \mathrm{L}$ sodium acetatetriethylamine ( $2: 2: 1$ by volume), and a third step after treatment for 10 min with $20 \mu \mathrm{L}$ of a derivatization reagent (methanol-triethylamine-water-PITC (Pierce); 7:1:1:1 by volume). After derivatization, the phenyltiocarbamyl amino acid derivatives were separated by gradient RP-HPLC on a $\mathrm{C}_{18}$ Pico-Tag physiological free amino acid column $(300 \times 3.9 \mathrm{~mm}$ (i.d.) $)$ at $46^{\circ} \mathrm{C}$, using a stated binary gradient of Waters eluents 1 and 2 at a flow rate of $1.0 \mathrm{~mL} / \mathrm{min}$. Separation took $65 \mathrm{~min}$.

To remove inter-batch analytical variation, all samples were assayed in a single continuous batch over 5 days. Daily, after random selection, a fifth of derivatized patient samples were dissolved in $100 \mu \mathrm{L}$ of the sample diluent (Waters) and $10 \mu \mathrm{L}$ was injected. To calculate intra-batch analytical variation, the first sample collected from each subject was deproteinized, derivatized and analyzed in duplicate. Single lots of reagents, eluents and calibrators were used and the assay was performed by a single analyst to minimize analytical variation. For routine quality control, aliquots of a lyophilized plasma pool, stored at $-20^{\circ} \mathrm{C}$, are analyzed with every batch. The assay is evaluated on a regular basis through participation in the ERNDIM external quality assessment (EQA) scheme (http://www.erndimqa.nl).

\section{Statistical analysis}

Statistical analysis was performed with SPSS software (11.0 for Windows, SPSS Inc, Chicago, IL, USA). A Gaussian distribution was assessed using the Shapiro-Wilk test and by verification of the straightness of a normal plot. Data for free plasma amino acids showed a Gaussian distribution. Thus, outliers were defined as those values exceeding $\pm 3 \mathrm{SD}$ and tested at two levels: individual data from every subject (within-subject data) and global data from all subjects (between-subjects data). After exclusion of outliers, biological variation data were estimated according to the method published by Fraser et al. $(13,14)$.

Analytical variance $\left(\mathrm{SD}_{\mathrm{A}}{ }^{2}\right)$ was calculated from the differences between the duplicates according to the formula:

$$
\mathrm{SD}_{\mathrm{A}}^{2}=\Sigma \mathrm{d}^{2} / 2 \mathrm{~N}
$$

where $\mathrm{d}$ is the difference between duplicates and $\mathrm{N}$ is the number of duplicates. The $\mathrm{SD}_{\mathrm{A}}{ }^{2}$ is expressed as relative $\mathrm{SD}_{\mathrm{A}}$ to the first sample concentration, analytical coefficient of variation $\left(\mathrm{CV}_{\mathrm{A}}\right)$. For each free plasma amino acid, one-way analysis of variance was used to divide the total variance into between-subject $\left(\mathrm{SD}_{\mathrm{G}}{ }^{2}\right)$ variance and total within-subject variance $\left(\mathrm{SD}_{\mathrm{TI}}{ }^{2}\right)$. Since $\mathrm{SD}_{\mathrm{TI}}{ }^{2}$ includes both biological and analytical components, the within-subject variance $\left(\mathrm{SD}_{\mathrm{I}}^{2}\right)$ was obtained by subtraction using the formula:

$$
\mathrm{S}_{\mathrm{I}}^{2}=\mathrm{S}_{\mathrm{TI}}^{2}-\mathrm{S}_{\mathrm{A}}^{2}
$$

Within-subject and between-subject biological variation was expressed as the coefficient of variation by the use of the homeostatic mean of each individual, within-subject coefficient of variation $\left(\mathrm{CV}_{\mathrm{I}}\right)$ and the overall mean, between-subject coefficient of variation $\left(\mathrm{CV}_{\mathrm{G}}\right)$, respectively. 
Biological variation data for free plasma amino acids were used to estimate the desirable quality specifications for I, B and TE, using the following formulas (19).

$\mathrm{I}=0.5 \mathrm{CV}_{\mathrm{I}}$

$\mathrm{B}=0.25\left(\mathrm{CV}_{\mathrm{I}}^{2}+\mathrm{CV}_{\mathrm{G}}{ }^{2}\right)^{1 / 2}$

$\mathrm{TE}=1.65\left(0.5 \mathrm{CV}_{\mathrm{I}}\right)+0.25\left(\mathrm{CV}_{\mathrm{I}}{ }^{2}+\mathrm{CV}_{\mathrm{G}}{ }^{2}\right)^{1 / 2}$

The II, which yields information regarding the utility of population-based reference intervals, was calculated as the ratio $\mathrm{CV}_{\mathrm{I}} / \mathrm{CV}_{\mathrm{G}}$ (16). The RCV, wich is the difference required for two serial results measurements to have clinically significantly changed at $p<0.05$, was calculated as in (17).

$\mathrm{RCV}=2^{1 / 2} 1.96\left(\mathrm{CV}_{\mathrm{A}}^{2}+\mathrm{CV}_{\mathrm{I}}^{2}\right)^{1 / 2}=2.77 \mathrm{CV}_{\mathrm{TI}}$

The NHSP for each amino acid with a statistical confidence of $95 \%$ and $\pm 20 \%$ accuracy was calculated as in (27):

$\mathrm{NHSP}=\left[1.96\left(\mathrm{CV}_{\mathrm{A}}^{2}+\mathrm{CV}_{\mathrm{I}}^{2}\right)^{1 / 2} / 20\right]^{2}$

\section{Results}

Of the 1350 data points, 44 were classified as outliers. The number of remaining data points for each amino acid is shown in Table 1. Data points excluded were below $10 \%$ for each amino acid, and a uniform distribution of these outliers was observed among samples and subjects. Also shown in Table 1 are the overall means, ranges, and the $\mathrm{CV}_{\mathrm{I}}$ and $\mathrm{CV}_{\mathrm{G}}$ for each amino acid. Also shown is the II, RCV and NHSP, which are derived from the data on biological variation. Because of the small sample size, significant differences in the $\mathrm{CV}$ between sexes cannot be demonstrated, therefore, only the totals are presented.

The $\mathrm{CV}_{\mathrm{I}}$ values observed for free plasma amino acids ranged from $9.5 \%$ to $46.4 \%$, with a median of $15.3 \%$. The $\mathrm{CV}$ values for essential amino acids were generally lower than that of the non-essential amino acids, for both withinand between-subjects, indicating tighter homeostatic control. Mean $\mathrm{CV}_{\mathrm{G}}$ was $46.6 \%$ and $\mathrm{CV}_{\mathrm{G}}$ was higher than $\mathrm{CV}_{\mathrm{I}}$ for all amino acids, with values for Pro and Trp over $100 \%$. As a result, the II values obtained for free plasma amino acids were below 1 (range, 0.2-0.8), with most being below 0.6. The RCV values, computed as a significant $(\mathrm{p}<0.05)$ change between serial results, ranged from $30.9 \%$ to $128.4 \%$, and values below $50 \%$ were observed for the essential amino acids. For most of the amino acids, 1-4 samples would be sufficient to provide an estimate of the homeostatic set point (within $\pm 20 \%$ with a confidence of $95 \%$ ), with the exception of Trp among the essential amino acids.

Table 1 Components of biological variation and derived parameters for free plasma amino acids.

\begin{tabular}{|c|c|c|c|c|c|c|c|c|}
\hline Amino acid & $\mathrm{n}^{\mathrm{a}}$ & $\begin{array}{l}\text { Mean, } \\
\mu \mathrm{mol} / \mathrm{L}\end{array}$ & Range, $\mu \mathrm{mol} / \mathrm{L}$ & $\begin{array}{l}\mathrm{CV}_{\mathrm{I}}^{\mathrm{b}} \\
\%\end{array}$ & $\begin{array}{l}\mathrm{CV}_{\mathrm{G}}^{\mathrm{c}} \text {, } \\
\%\end{array}$ & II $^{\mathrm{d}}$ & $\begin{array}{l}\mathrm{RCV}^{\mathrm{e}} \\
\%\end{array}$ & $\mathrm{NHSP}^{\mathrm{f}}$ \\
\hline $\mathrm{Abu}^{\mathrm{g}}$ & 52 & 21.1 & $9.2-33.2$ & 24.7 & 32.3 & 0.8 & 73.0 & 7 \\
\hline Ala & 54 & 405.7 & $215.8-597.7$ & 14.7 & 55.8 & 0.3 & 41.3 & 2 \\
\hline Arg & 51 & 81.4 & $45.3-130.1$ & 19.3 & 34.1 & 0.6 & 54.3 & 4 \\
\hline Asn & 54 & 128.7 & $85.6-177.4$ & 12.3 & 28.0 & 0.4 & 35.0 & 2 \\
\hline Asp & 50 & 2.9 & $0.8-5.3$ & 31.2 & 55.1 & 0.6 & 88.2 & 10 \\
\hline Cit & 51 & 57.6 & $11.7-84.5$ & 21.4 & 43.9 & 0.5 & 62.7 & 5 \\
\hline$(\mathrm{Cys})_{2}{ }^{\mathrm{h}}$ & 53 & 22.2 & $5.5-44.1$ & 38.3 & 48.5 & 0.8 & 112.3 & 16 \\
\hline Glu & 50 & 58.8 & $25.1-155.7$ & 46.4 & 79.9 & 0.6 & 128.4 & 21 \\
\hline Gln & 52 & 546.3 & $350.2-676.6$ & 12.1 & 22.0 & 0.6 & 34.0 & 2 \\
\hline Gly & 54 & 211.1 & $117.9-338.9$ & 11.8 & 40.3 & 0.3 & 33.0 & 1 \\
\hline His & 53 & 62.2 & $40.6-81.5$ & 9.7 & 27.2 & 0.4 & 36.2 & 1 \\
\hline Hyp $^{\mathrm{i}}$ & 50 & 12.0 & $0.8-28.6$ & 34.5 & 56.7 & 0.6 & 96.5 & 12 \\
\hline Ile & 53 & 46.4 & $27.6-79.4$ & 15.5 & 45.5 & 0.3 & 46.0 & 3 \\
\hline Leu & 53 & 136.8 & $85.7-248.4$ & 14.8 & 44.0 & 0.3 & 44.1 & 2 \\
\hline Lys & 53 & 164.9 & $102.7-231.0$ & 11.5 & 38.2 & 0.3 & 33.7 & 1 \\
\hline Met & 53 & 28.3 & $12.2-42.7$ & 14.7 & 43.4 & 0.3 & 41.9 & 2 \\
\hline Orn & 53 & 51.1 & $25.5-99.9$ & 18.4 & 54.9 & 0.3 & 52.5 & 3 \\
\hline Phe & 52 & 63.0 & 38.7-96.1 & 9.5 & 40.6 & 0.2 & 30.9 & 1 \\
\hline Pro & 52 & 276.0 & $137.3-620.2$ & 17.0 & 104.4 & 0.2 & 58.1 & 3 \\
\hline Ser & 52 & 108.6 & $56.1-158.0$ & 12.8 & 42.8 & 0.3 & 36.0 & 2 \\
\hline $\mathrm{Tau}^{\mathrm{j}}$ & 53 & 63.6 & $32.2-120.9$ & 30.6 & 44.0 & 0.7 & 85.3 & 9 \\
\hline Thr & 54 & 143.0 & $82.3-215.6$ & 17.9 & 33.1 & 0.5 & 50.7 & 3 \\
\hline $\operatorname{Trp}$ & 52 & 27.3 & $7.9-81.9$ & 22.7 & 152.6 & 0.2 & 65.8 & 6 \\
\hline Tyr & 52 & 73.3 & $40.4-127.5$ & 10.5 & 61.0 & 0.2 & 31.1 & 1 \\
\hline Val & 51 & 220.1 & $128.1-324.9$ & 10.6 & 40.1 & 0.3 & 32.3 & 1 \\
\hline
\end{tabular}

${ }^{\mathrm{a}} \mathrm{n}$, number of data available for each amino acid after the exclusion of outliers; ${ }^{\mathrm{b}} \mathrm{CV}_{\mathrm{I}}$, within-subject coefficient of variation; ${ }^{\mathrm{c}} \mathrm{CV}_{\mathrm{G}}$, betweensubject coefficient of variation; ${ }^{\mathrm{d} I I}$, index of individuality; ${ }^{\mathrm{e}} \mathrm{RCV}$, reference change value (bi-directional $95 \%$ confidence); ${ }^{\mathrm{f}} \mathrm{NHSP}$, number of samples required to estimate the homeostatic setting point (95\% confidence, $20 \%$ accuracy); ${ }^{\mathrm{g}} \mathrm{Abu}, \alpha$-aminobutyric acid; ${ }^{\mathrm{h}}(\mathrm{Cys}){ }_{2}$, cystine; ${ }^{i}$ Hyp, hidroxiproline; ${ }^{j}$ Tau, taurine. 
Duplicate samples were used to calculate intra-batch imprecision. The $\mathrm{CV}_{\mathrm{A}}$ values are shown in Table 2. Differences in duplicate data for free plasma amino acids showed a Gaussian distribution with the exception of Pro which required log-transformation of the raw data. For each plasma amino acid, the between-batch imprecision from 11 routine analyses performed over three months and the desirable quality specifications for I, B and TE derived from biological variation data are presented in Table 2 . The $\mathrm{CV}_{\mathrm{A}}$ of our laboratory method were less than the desirable imprecision goals for all amino acids except His and Phe for the intrabatch imprecision, and His, Phe or Lys for inter-batch imprecision. TE values ranged from $15.2 \%$ to $61.0 \%$, with a median of $23.6 \%$ for the essential and $30.1 \%$ for the nonessential amino acids.

\section{Discussion}

The increasing interest in the application of biological variation data has prompted the study of several "esoteric" analytes, such as N-terminal pro-brain natriuretic peptide (28), blood vitamins (29) or asymmetric dimethylarginine (30). However, to our knowledge, no previous specifically designed studies on biological variation have been reported for free plasma amino acids. We have generated biological variation data for free plasma amino acids using an experi- mental protocol which represents a trade-off between the long analytical run times required per analysis, and the recommended duplicate examination in a single analytical batch (13). The random duplicate analysis of the first sample collected from each subject allowed us to estimate the analytical variation keeping an adequate number of subjects and specimens.

Free plasma amino acids exhibit relatively low $\mathrm{CV}_{\mathrm{I}}$ values, similar to those reported for other diet related metabolites such as, plasma vitamins (29). The essential amino acids showed lower $\mathrm{CV}_{\mathrm{I}}$ than non-essential amino acids. This probably reflects differences in metabolic control since the non-essential amino acids would be more influenced by potential changes in physiologic conditions between sampling dates $(1,20)$. Prior et al. (31), in a study of conditions altering plasma concentrations of amino acids in elderly women, generated estimates of biological variation and described equivalent $\mathrm{CV}_{\mathrm{I}}$ data and similar differences between the $\mathrm{CV}_{\mathrm{I}}$ values for essential and non-essential amino acids. In contrast, our study shows higher $\mathrm{CV}_{\mathrm{G}}$ values for the majority of plasma amino acids compared with those observed by Prior et al. in fasted elderly subjects. Differences in populations studied and experimental protocols may explain these discrepancies.

The utility of population-based reference intervals in clinical decision-making depends on the individuality of the analyte (16), which is expressed as II. When the II is $<0.6$, the

Table 2 Assay imprecision and desirable specifications derived from biological variation data.

\begin{tabular}{|c|c|c|c|c|c|}
\hline Amino acid & $\begin{array}{l}\mathrm{CV}_{\mathrm{A}} \text { intra }^{\mathrm{a}}, \\
\%\end{array}$ & $\begin{array}{l}\mathrm{CV}_{\mathrm{A}} \text { inter }^{\mathrm{b}}, \\
\%\end{array}$ & $\begin{array}{l}\mathrm{I}^{\mathrm{c}}, \\
\%\end{array}$ & $\begin{array}{l}\mathrm{B}^{\mathrm{d}} \\
\%\end{array}$ & $\begin{array}{l}\mathrm{TE}^{\mathrm{e}}, \\
\%\end{array}$ \\
\hline $\mathrm{Abu}^{\mathrm{f}}$ & 9.3 & 9.9 & 12.3 & 10.2 & 30.5 \\
\hline Ala & 2.7 & 4.0 & 7.3 & 14.4 & 26.5 \\
\hline Arg & 3.0 & 3.3 & 9.7 & 9.8 & 25.8 \\
\hline Asn & 3.1 & 4.6 & 6.1 & 7.6 & 17.7 \\
\hline Asp & 5.7 & 6.4 & 15.6 & 15.8 & 41.7 \\
\hline Cit & 7.2 & 7.4 & 10.7 & 12.2 & 47.2 \\
\hline$(\mathrm{Cys})_{2}{ }^{\mathrm{g}}$ & 13.3 & 15.9 & 19.1 & 15.4 & 47.0 \\
\hline Glu & 2.6 & 3.8 & 23.1 & 23.1 & 61.0 \\
\hline Gln & 2.1 & 2.9 & 6.0 & 6.3 & 16.2 \\
\hline Gly & 1.4 & 3.2 & 5.9 & 10.5 & 20.2 \\
\hline His & 5.5 & 5.5 & 4.9 & 7.2 & 15.2 \\
\hline Hyp $^{h}$ & 4.3 & 8.3 & 17.3 & 16.6 & 45.1 \\
\hline Ile & 5.8 & 6.1 & 7.8 & 12.0 & 24.9 \\
\hline Leu & 5.9 & 6.2 & 7.4 & 11.6 & 23.8 \\
\hline Lys & 4.0 & 9.4 & 5.7 & 10.0 & 19.4 \\
\hline Met & 3.6 & 7.3 & 7.3 & 11.5 & 23.6 \\
\hline Orn & 4.4 & 9.2 & 9.2 & 14.5 & 29.7 \\
\hline Phe & 5.9 & 6.0 & 4.7 & 10.4 & 18.2 \\
\hline Pro & 1.5 & 3.0 & 10.4 & 26.4 & 40.1 \\
\hline Ser & 2.3 & 2.8 & 6.4 & 11.2 & 21.7 \\
\hline $\mathrm{Tau}^{\mathrm{i}}$ & 3.5 & 4.7 & 15.3 & 13.4 & 38.6 \\
\hline Thr & 3.7 & 4.3 & 8.9 & 9.4 & 24.1 \\
\hline Trp & 6.7 & 8.1 & 11.4 & 38.6 & 48.0 \\
\hline Tyr & 3.9 & 4.0 & 5.2 & 15.5 & 24.1 \\
\hline Val & 5.0 & 5.0 & 5.3 & 10.4 & 19.1 \\
\hline
\end{tabular}

${ }^{\mathrm{a}} \mathrm{CV}_{\mathrm{A}}$ intra, intra-batch analytical imprecision; ${ }^{\mathrm{b}} \mathrm{CV}_{\mathrm{A}}$ inter, inter-batch analytical imprecision; ${ }^{\mathrm{I}} \mathrm{I}$, imprecision; ${ }^{\mathrm{d}} \mathrm{B}$, bias; ${ }^{\mathrm{e}} \mathrm{TE}$, total error; ${ }^{\mathrm{f}} \mathrm{Abu}$, $\alpha$-aminobutyric acid; ${ }^{\mathrm{g}}(\mathrm{Cys})_{2}$, cystine; ${ }^{\mathrm{h}} \mathrm{Hyp}$, hidroxiproline; ${ }^{\mathrm{T}} \mathrm{Tau}$, taurine. 
analyte shows high individuality and a single result compared with the reference interval is considered to have little diagnostic value. In contrast, when II is $>1.4$, the analyte shows low individuality and reference intervals are clinically useful $(13,14)$. In our study, the II was $<0.8$ for all amino acids studied, indicating the limited diagnostic utility of reference intervals in the context of nutritional assessment. Comparison of serial results from the amino acid profile for an individual seems to be of most value for appropriate clinical interpretation.

The RCV is an important clinical tool for the assessment of changes in patients being monitored in pathological situations $(14,17)$. The RCVs were high for amino acids primarily due to their within-subject component of variation, a common finding in other diet-related metabolites studied in plasma (29). Therefore, relatively large differences between results of sequential samples would be required, i.e., a difference of $31 \%$ between two consecutive results in hyperphenylalaninemia monitoring would be necessary to indicate significant changes as a result of treatment. Interestingly, $<3-4$ sampling days are needed to establish characteristic concentrations for the majority of the amino acids, according to biological variation data.

The European consensus established that the best quality specifications in laboratory medicine are those based on biological variation $(19,20)$. Also, a desirable analytical CV of 0.5 times $\mathrm{CV}_{\mathrm{I}}$ is usually considered because this assay imprecision adds only a $12 \%$ to the data variability. This desirable goal for imprecision was widely fulfilled in our laboratory for free plasma amino acids, except for His, Phe and Lys. As a consequence of their lower $\mathrm{CV}_{\mathrm{I}}$, these essential amino acids would require more stringent assay performance, although the measurement easily meets the minimum goal for imprecision $\left(0.75 \mathrm{CV}_{\mathrm{I}}\right)$. In addition, it has been proposed (32) that EQA schemes should use TE based on biology for describing the maximum allowable error for single determinations of quality-control materials. Therefore, it is hoped that these biological variation data may serve to apply this approach in the analysis of free plasma amino acids.

In summary, we generated biological variation data for free plasma amino acids, observing relatively low $\mathrm{CV}_{\mathrm{I}}$ values, especially for some essential amino acids like His, Phe and Val. Analytical quality specifications were derived from biological variation data, and imprecision goals can be reasonably achieved with current methods. Reference intervals for free plasma amino acids are of limited value in the detection of unusual results for a particular individual, and sequential analysis of the amino acids profile by means of the $\mathrm{RCV}$ is recommended.

\section{Acknowledgements}

This research was partially supported by a grant from the Fondo de Investigación Sanitaria to RV (FIS 02/0665). The authors thank the subjects who participated in the study and J. Muñiz for the excellent technical assistance.

\section{Conflict of interest statement}

Authors' conflict of interest disclosure: The authors stated that there are no conflicts of interest regarding the publication of this article.

Research funding: None declared.

Employment or leadership: None declared.

Honorarium: None declared.

\section{References}

1. Blau N, Duran M, Blaskovics ME, Gibson KM. Physician's guide to the laboratory diagnosis of metabolic diseases, 2nd ed. Berlin: Springer-Verlag, 2003.

2. Bremer HJ, Duran M, Kamerling JP, Przyrembel H, Wadman SK. Disturbance of amino acid metabolism: clinical chemistry and diagnosis. Baltimore: Urban \& Schwarzenberg, 1981.

3. Longo N. Inherited disorders of amino acid metabolism in adults. In: Kasper DL, Braunwald E, Hauser S, Longo N, Jameson JL, Fauci AS, editors. Harrison's principles of internal medicine, 6th ed. Blacklick, Ohio: McGraw Hill Professional, 2004: 2387-90.

4. Acosta PB. Nutrition support of inborn errors of metabolism. In: Samour PQ, King K, editors. Handbook of pediatric nutrition, 3rd ed. Sudbury, Mass: Jones \& Bartlett, 2005:239-87.

5. Rudman D, Mattson DE, Feller AG, Cotter R, Johnson RC. Fasting plasma amino acids in elderly men. Am J Clin Nutr 1989;49:559-66.

6. Caballero B, Gleason RE, Wurtman RJ. Plasma amino acids concentrations in healthy elderly men and women. Am J Clin Nutr 1991;53:1249-52.

7. Palova S, Charvat J, Masopust J, Klapkova E, Kvapil M. Changes in the plasma amino acid profile in anorexia nervosa. J Int Med Res 2007;35:389-94.

8. Ivarsen P, Tietze IN, Pedersen EB. Nutritional status and amino acids in granulocytes and plasma in patients with chronic renal disease and varying residual renal function. Nephron 2001;88: 224-32.

9. Chuang CK, Lin SP, Chen HH, Chen YC, Wang TJ, Shieh WH, et al. Plasma free amino acids and their metabolites in Taiwanese patients on hemodialysis and continuous ambulatory peritoneal dialysis. Clin Chim Acta 2006;364:209-16.

10. Malgorzewick S, Debska-Slizien A, Rutkowski B, LysiakSzydlowska W. Serum concentration of amino acids versus nutritional status in hemodialysis patients. J Ren Nutr 2008; 18 : 239-47.

11. Henkel AS, Buchman AL. Nutritional support in chronic liver disease. Nat Clin Pract Gastroenterol Hepatol 2006;3:202-9.

12. Schulte-Frohlinde E, Wagenpfeil S, Willis J, Lersch C, Eckel F, Schmid R, et al. Role of meal carbohydrate content for the imbalance of plasma amino acids in patients with liver cirrhosis. J Gastroenterol Hepatol 2007;22:1241-8.

13. Fraser CG, Harris EK. Generation and application of data on biological variation in clinical chemistry. Crit Rev Clin Lab Sci 1989;27:409-37.

14. Fraser CG. Biological variation: from principles to practice. Washington DC: AACC Press, 2001.

15. Henry J, Peticlerc C, Fuentes-Arderiu X, Petersen PH, Queraltó JM, Schiele F, et al. Need for revising the concept of reference values. Clin Chem Lab Med 2000;38:589-95. 
16. Fraser CG. Inherent biological variation and reference values. Clin Chem Lab Med 2004;42:758-64.

17. Ricos C, Cava F, García-Lario JV, Hernandez A, Iglesias N, Jiménez CV, et al. The reference change value: a proposal to interpret laboratory reports in serial testing based on biological variation. Scan J Clin Lab Invest 2004;64:175-84.

18. Ricos C, Iglesias N, Garcia-Lario JV, Simon M, Cava F, Hernandez A, et al. Within-subjects biological variation in disease: collates data and clinical consequences. Ann Clin Biochem 2007;44:343-52.

19. Fraser CG, Hyltoft Petersen P. Analytical performance characteristics should be judged against objective quality specifications. Clin Chem 1999;45:321-3.

20. Petersen PH, Fraser CG, Jorgensen L, Brandslund I, Stahl M, Gowans E, et al. Combination of analytical quality specifications based on biological within- and between-subjects variation. Ann Clin Biochem 2002;39:543-50.

21. Le Boucher J, Charret C, Coudray-Lucas C, Giboudeau J, Cynober L. Amino acid determination in biological fluids by automated ion-exchange chromatography: performance of Hitachi L-8500A. Clin Chem 1997;43:1421-8.

22. Fekkes D. State-of-art of high-performance liquid chromatographic analysis of amino acids in physiological samples. J Chrom 1996;682:3-22.

23. Fekkes D, Voskuilen-Kooyman A, Jankie R, Huijmans J. Precise analisys of primary amino acids in urine by an automated high-performance liquid chromatography method: comparison with ion-exhance chromatography. J Chromatogr B Biomed Sci Appl 2000;744:183-8.

24. Ricos C, Alvarez V, Cava F, Garcia-Lario JV, Hernandez A, Jiménez CV, et al. Current databases on biological variation: pos, cons and progress. Scand J Clin Lab Invest 1999;59:491500 .

25. Ricos C, Garcia-Lario JV, Alvarez V, Cava F, Doménech M, Hernandez A, et al. Biological variation database, and quality specifications for imprecision, bias and total error (desirable and minimum). The 2008 update. < http://www.westgard.com/ guest36.htm $>$. Accessed February 22, 2009.

26. Cohen SA, Meys M, Tarwin TL. The Pico Tag method: a manual of advanced techniques for amino acid analysis, Rev. 1. Bedford (MA): Millipore, 1989.

27. Fraser CG. Are "scientific statements" the scientific truth? $<$ http://www.westgard.com/guest23.htm $>$. Accessed February 22, 2009.

28. Melzi d'Eril G. Biological varition of N-terminal pro brain natriuretic peptide in healthy individuals. Clin Chem 2003;49: 1554-5.

29. Talwar DK, Azharuddin MK, Williamson C, Teoh YP, McMillan DC, O'Reilly DSJ. Biological variation of vitamins in blood of healthy individuals. Clin Chem 2005;51:2145-50.

30. Blackwell S, O'Reilly J, Talwar D. Biological variation of asymmetric dimethylarginine and related arginine metabolites and analytical performance goals for their measurement in human plasma. Eur J Clin Invest 2007;37:364-71.

31. Prior LR, Crim MC, Castaneda C, Lammi-Keefe B, DawsonHughes CJ, Rosen J, et al. Conditions altering plasma concentrations of urea cycle and other amino acids in elderly human subjets. J Am Coll Nutr 1996;15:237-47.

32. Fraser CG, Petersen PH. Quality goals in external quality assessment are best base on biology. Scand J Clin Lab Invest 1993;53(Suppl 212):8-9. 